\title{
HIGH-FREQUENCY INDUCTION OF MULTIPLE SHOOTS AND PLANT REGENERATION FROM COTYLEDONARY NODE EXPLANTS OF TONGKAT ALI (EURYCOMA LONGIFOLIA JACK)
}

\author{
AltTAher, A. G. A. ${ }^{1}-$ Yusof, Z. N. B. ${ }^{1}-$ MAhmood, M. $^{1}-$ Shaharuddin, N. A. ${ }^{1,2^{*}}$ \\ ${ }^{I}$ Department of Biochemistry, Faculty of Biotechnology and Biomolecular Sciences, University \\ Putra Malaysia, 43400 Serdang, Selangor, Malaysia \\ ${ }^{2}$ Institute of Tropical Agriculture and Food Security, University Putra Malaysia, Serdang, \\ Selangor 43400, Malaysia \\ *Corresponding author \\ e-mail:noorazmi@upm.edu.my; phone: +60-397-696-724; fax: +60-397-697-590
}

(Received $19^{\text {th }}$ Feb 2020; accepted $9^{\text {th }}$ Jul 2020)

\begin{abstract}
Eurycoma longifolia Jack is traditionally used as an aphrodisiac and health supplement for various diseases. Due to its potential commercial value as a plantation crop as well as to conserve its germplasm, it is necessary to establish a suitable protocol of propagation as a better alternative for mass production. Hence, this study describes an efficient and reproducible in vitro regeneration system of E. longifolia. Cotyledonary node explants were excised from 2-week-old in vitro seedlings and cultured on Murashige and Skoog (MS) medium supplemented with different concentrations of 6-benzyl aminopurine (BAP), kinetin (KIN) and thidiazuron (TDZ). In addition, various concentrations of indole-3-butyric acid (IBA) and $\alpha$ - naphthaleneacetic acid (NAA) were tested for in vitro rooting of shoots. From the results, it was observed that $1.0 \mathrm{mgL}^{-1}$ of BAP induced the highest percentage of shoot formation (76.7\%) from cotyledonary node explants. The best rooting response was observed on half-strength MS medium containing $0.5 \mathrm{mgL}^{-1} \mathrm{IBA}$ with an average of 3.2 roots per shoot. Regenerated plantlets were successfully acclimatized to ex vitro conditions with an $85 \%$ survival rate. Overall, this in vitro regeneration protocol provides a rapid technique that can be utilized for commercial propagation and genetic transformation of this medicinal plant.
\end{abstract}

Keywords: seed germination, shoot multiplication, in vitro rooting, acclimatization, cytokinin and auxins

\section{Introduction}

Medicinal plants have been an essential part of the ethnobotanical aspect of the people around the world since ancient times. Today, the majority of people are still relying on traditional remedies to meet their primary health care needs (Parveen et al., 2010; Uprety et al., 2012; Alsarhan et al., 2014; Jamshidi-Kia et al., 2018). Eurycoma longifolia Jack or Tongkat Ali as locally known in Malaysia is an important medicinal plant belonging to the family Simaroubaceae. Due to its diverse medicinal values, every part of the plant is used as medicine, especially the roots (Rahmawati and Esyanti, 2014; Yahya et al., 2015). The traditional use of the Tongkat Ali root extracts as anti-inflammatory and analgesic remedies is well established. Studies have revealed that the root extracts of Tongkat Ali have antimalarial, cytotoxic, aphrodisiac, antioxidant, anti-tumor, antiinflammatory, anti-pyretic, and anti-amoebic properties, and also it has been applied in the treatment of diverse conditions such as fatigue, impotence, loss of sexual desire, high blood pressure and fever (Bhat and Karim, 2010; Rehman et al., 2016). Conventional propagation of Tongkat Ali via seed germination is considered as the most common method for the plant propagation, but as a woody plant, it is difficult for several reasons 
such as low rate of seed germination and poor flowering (Keng et al., 2002; Rahmawati and Esyanti, 2014; Thu et al., 2016).

Being a recalcitrant plant, the seeds took a long time to germinate and have the lowest percentage of germination due to immaturation of the zygotic embryo (Ayoba et al., 2013; Zeng et al., 2014). Furthermore, Tongkat Ali roots were harvested after 4-7 years of cultivation, so the production of the roots is time-consuming, and fluctuated depending on the seasons (Chua et al., 2011). Therefore, the tissue culture technique was an urgent need for rapid propagation on a commercial scale to meet the pharmaceutical industry demand (Lulu et al., 2015). Previously, efforts have been conducted on Tongkat Ali regeneration using different explants such as shoot tips, roots, stems, leaves, and cotyledons (Hussein et al., 2005, 2012; Mahmood et al., 2010; Rodziah and Madihah, 2015). However, regeneration protocols on Tongkat Ali are not well developed; mainly due to the recalcitrant nature of plants. Direct shoot regeneration through the organogenesis provides a better solution for propagation within a short period of time and less soma clonal variability (Juturu et al., 2015).

Development of suitable in vitro regeneration protocols is one of the major prerequisites for improvement of genetic characters of plants using biotechnological methods (Venkatachalam and Kavipriya, 2012; Singh et al., 2015). Although in vitro propagation was an alternative method for mass production and conservation, studies had shown that shoot induction of recalcitrant species still rare due to its woody nature (Hussein et al., 2012; Isah, 2016). As an important plant in folk medicinal practices, an efficient propagation protocol is urgently needed to fulfil the market demand for Tongkat Ali. In vitro micropropagation provides an alternative solution for obstacles faced by the conventional method of propagation. It can also be applied as a strategy for conservation and utilization of genetic resources (Groach and Singh, 2015; Singh, 2018). Thus, the current study reported a rapid micropropagation system of E. longifolia through cotyledonary node explants by using different concentrations of various plant growth regulators.

\section{Material and methods}

\section{Plant material and seed germination}

The plant material used in this study was provided by Institute of Bioscience, University Putra Malaysia. All experimental procedures were carried out at Plant Biochemistry and Biotechnology Laboratory of Biochemistry Department at University Putra Malaysia. Matured ripe dark-red fruits of Tongkat Ali were washed with detergent and rinsed under running tap water for 30 minutes. Then the epicarp and mesocarp of the fruits were manually removed (Fig. 1B). Surface-sterilization of seeds was carried out in laminar-flow hood according to procedure described by Mahmood et al. (2010) as follows: seeds soaked for 5 minutes in $70 \%$ (v/v) ethanol; and then submersed for 20 minutes in $20 \%$ (v/v) Clorox ${ }^{\circledR}$ plus two drops of Tween-20; after that the seeds were rinsed with sterile distilled water five times. In vitro seed germination was carried out to ensure aseptic growth conditions of seedlings that would be used as a source of explants (cotyledonary nodes). After sterilization, the seed coat was removed to accelerate the rate of germination and help to avoid any phenolic compounds that naturally released in culture media from seed coats (Fig. 1C,D). Embryos were inoculated into $15 \times 2.5 \mathrm{~cm}$ vials containing $20 \mathrm{~mL}$ of full-strength Murashige and Skoog (1962) (MS) medium without plant growth regulators (PGRs) (Fig. 1E,F). 

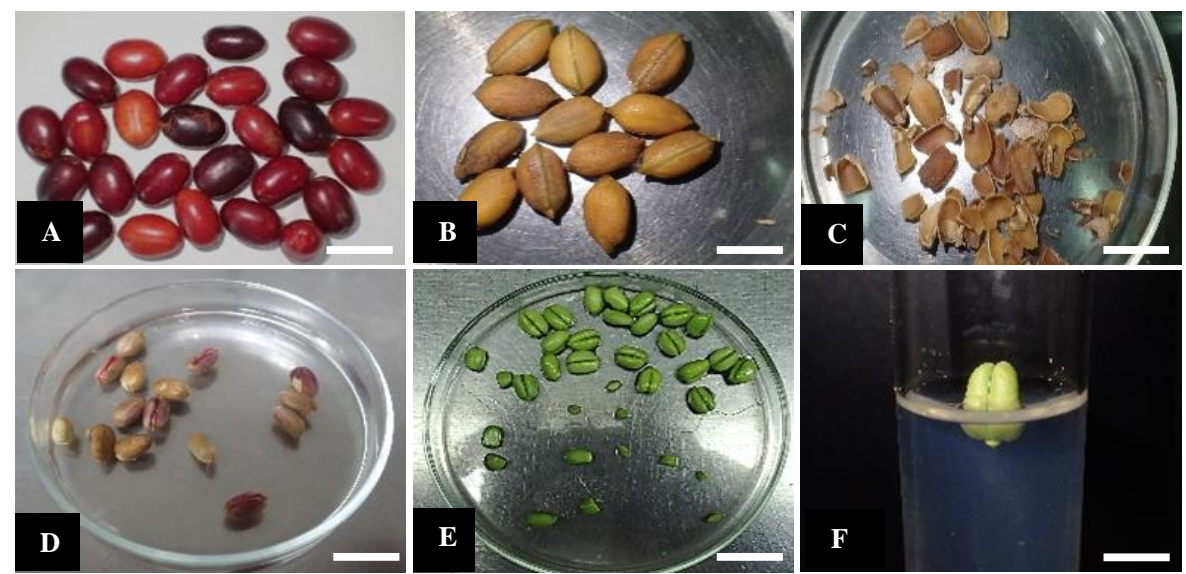

Figure 1. Preparation of seeds for in vitro germination, (A) Eurycoma longifolia fruits, (B) removing the epicarp and mesocarp $(C, D)$ removing of the seed coat $(E)$ isolated embryos ready for inoculation $(F)$ inoculation of the embryo on germination media $($ Bars $=1 \mathrm{~cm})$

\section{Culture medium and conditions}

All experiments were conducted using MS medium with the addition of $3 \%$ sucrose, and various concentrations of PGRs. A medium without any PGRs was included as a control. Culture medium solidified with $0.25 \%$ Gelrite, and the $\mathrm{pH}$ of culture medium was set to 5.8 using $\mathrm{HCl}$ or $1 \mathrm{~N} \mathrm{NaOH}$ prior autoclaving for 20 minutes at $121^{\circ} \mathrm{C}$ and $1.06 \mathrm{~kg} \mathrm{~cm}^{-2}$ pressure. All cultures were initially maintained in the growth room in the dark at $25 \pm 2{ }^{\circ} \mathrm{C}$ for 1 week, then transferred to $8 \mathrm{~h}$ dark and $16 \mathrm{~h}$ light photoperiod supplied by cool white fluorescent bulbs $\left(35 \mu \mathrm{mol} \mathrm{m} \mathrm{m}^{-2} \mathrm{~s}^{-1}\right.$ photon flux density). Relative humidity was maintained at $60 \%$.

\section{Shoot induction from cotyledonary node explants}

Cotyledons nodes were excised from 14-day-old in vitro raised seedlings (Fig. 2C) under sterile conditions and used as explants. The cotyledonary node explants with intact embryonic axis were cultured on MS medium supplemented with different concentrations $\left(0.2,0.5,1.0,2.0\right.$ and $\left.3.0 \mathrm{mgL}^{-1}\right)$ of 6-benzylaminopurine (BAP) and kinetin (KIN) as well as thidiazuron (TDZ) at concentrations $\left(0.1,0.2,0.5,1.0\right.$ and $\left.2.0 \mathrm{mgL}^{-1}\right)$. Data on shoot regeneration percentage, number of shoots per explant and shoot length were frequently recorded every week of culture. For shoots proliferation, the shoots were regularly sub-cultured at six-week intervals onto the fresh MS medium containing the same cytokinin composition. After harvesting the multiple shoots, the original cotyledonary nodes were recultured on a fresh medium for further shoot multiplication.

\section{In vitro rooting and acclimatization}

In order to obtain a complete plantlet, regenerated shoots $(2.5-4.5 \mathrm{~cm}$ in length) were aseptically excised and transferred to rooting medium comprising of half-strength MS medium without auxins or with auxins such as indole-3-butyric acid (IBA) or naphthaleneacetic acid (NAA) at different concentrations $\left(0.2,0.5,1.0\right.$ and $\left.2.0 \mathrm{mgL}^{-1}\right)$. The observations on root induction percentage, root number and root length were recorded weekly. Acclimatization was initially carried out in the laboratory as follows: plantlets that have vigorous shoots with a well-developed root system were gently 
removed from the culture medium and washed carefully with autoclaved distilled water to remove the traces of nutrient medium from the roots. Then the plantlets potted in $7.5 \mathrm{~cm}$ plastic pots containing an autoclaved jiffy- 7 medium. Plantlets were watered and immediately covered with transparent polyethylene bags to maintain high humidity around the plantlets. The plantlets were maintained in the growth room at $25 \pm 2{ }^{\circ} \mathrm{C}$ in $16 \mathrm{~h}$ light and $8 \mathrm{~h}$ dark photoperiod $\left(35 \mu \mathrm{mol} \mathrm{m}^{-2} \mathrm{~s}^{-1}\right.$ photon flux density supplied by cool white fluorescent bulbs). After two weeks the humidity around the plantlets was gradually reduced by puncturing the polyethylene bags with small holes. Finally, the polyethylene bags were removed and plantlets were shifted to big plastic $18 \mathrm{~cm}$-pots containing garden soil. These plantlets were then kept under natural day light conditions (12/12-h of light/ dark photoperiod) at the greenhouse for normal growth.

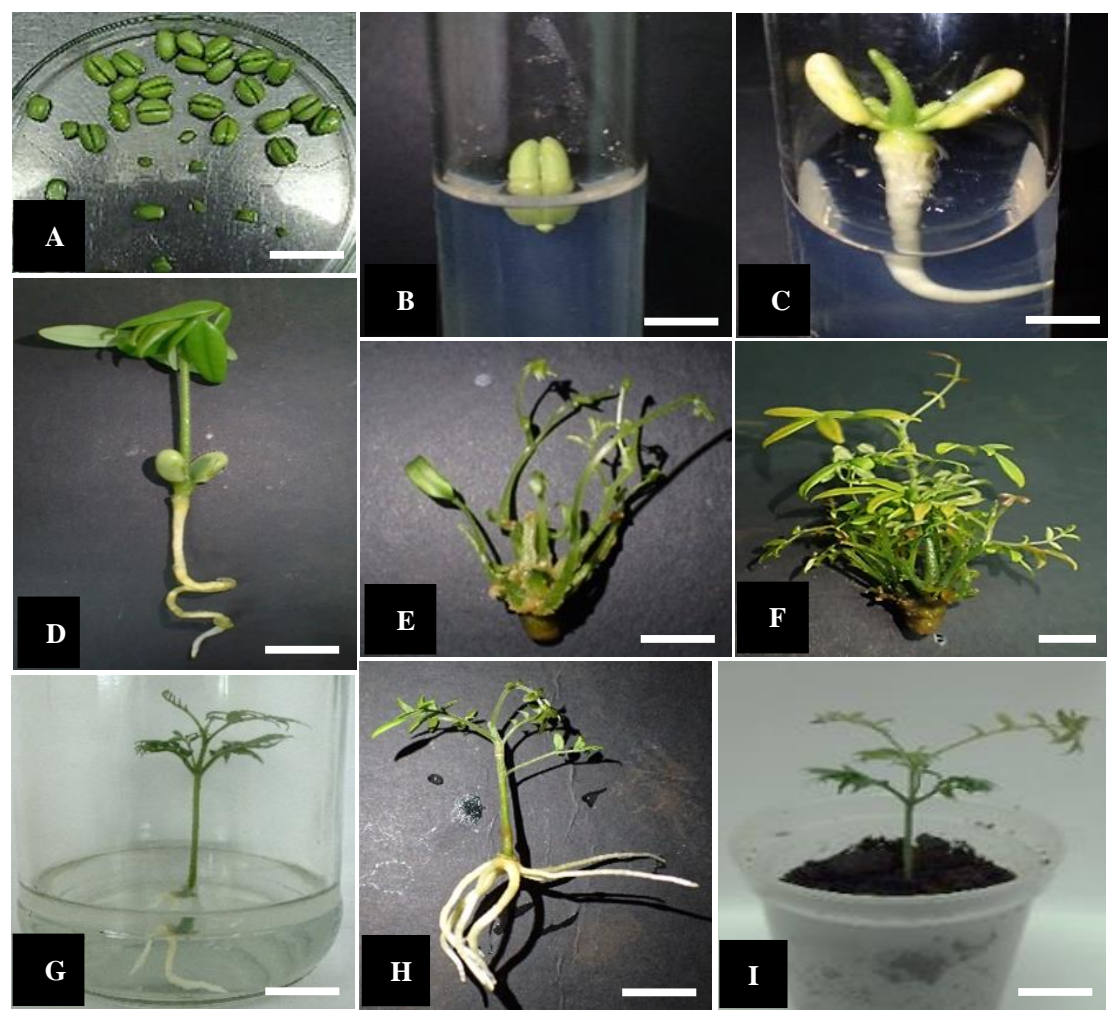

Figure 2. Multiple shoots formation from a cotyledonary node explants of Eurycoma longifolia.

(A) removing the epicarp and mesocarp of the fruits and seed coat from the seed. (B) seed cultured on MS medium with different concentration of cytokinin. $(C)$ seed germination. $(D)$ formation of multiple shoots. (E) shoot proliferation from a cotyledonary node explant on MS BAP $1.0 \mathrm{mgL}^{-1}$. (F) In vitro rooting of shoots on MS medium supplemented with $0.5 \mathrm{mgL}^{-1} I B A$.

(G) formation of the root system after 6 weeks. $(H)$ plantlet transferred to jiffy-7 potting medium. (I) acclimatized plantlets (Bars $=1 \mathrm{~cm}$ )

\section{Statistical analysis}

All experiments were designed as a complete randomized design (CRD) with 10 replicates and repeated three times. The percentage of seed germination was calculated with the following Equation 1 (Keng et al., 2002).

$$
\frac{n}{N} \times 100 \%
$$


In Equation 1, $\mathrm{n}$ is the number of seeds germinated and $\mathrm{N}$ is the total number of seeds used in each germination treatment. The observations on the treatments were recorded weekly. Finally, the data obtained were subjected to ANOVA (one-way analysis of variance) to examine whether they were statistically significantly different from each other or not using Minitab software. Means were subjected to Tukey's test $(p \leq 0.05)$ and the results were expressed as means \pm standard errors (SE).

\section{Results}

\section{Effects of plant growth regulators on shoot bud induction}

Types of plant growth regulators (PGRs) and their concentrations have been reported to influence organogenesis in plants, as evidenced in this study with the multiplication of shoots from cotyledonary node explants. As shown in Table 1, frequency, number and length of multiple shoots formed varied significantly with PGRs supplementations. Variance analysis revealed that shoot proliferation rates differed significantly $(\mathrm{P} \leq 0.05)$ based on concentrations and type of cytokinin used. The three cytokinins, namely BAP, KIN and TDZ at different concentrations were tested for their ability to induce multiple shoots. Multiple shoots were initially formed from cotyledonary node explants within 15 to 20 days in the presence of cytokinins (Fig. 2D). These multiple shoots were induced by supplementing the media with $0.2-3.0 \mathrm{mgL}^{-1} \mathrm{BAP}$, KIN or $0.1-2.0 \mathrm{mgL}^{-1} \mathrm{TDZ}$. Cotyledonary node explants cultured on MS medium without the PGRs (as a negative control) did not give response to shoot buds formation. Among different cytokinins tested, BAP at a concentration of $1.0 \mathrm{mgL}^{-1}$ showed the highest frequency of multiple shoots induction $(76.7 \%)$ with the maximum shoot number $(4.87 \pm 0.70)$ shoot per explant compared to other concentrations of KIN or TDZ (Table 1, Fig. 2E). For shoot proliferation, cotyledonary nodes were regularly subcultured onto fresh medium of the same composition of PGRs.

Table 1. Effect of different cytokinins concentrations on shoot induction from cotyledonary node explants of Eurycoma longifolia

\begin{tabular}{|c|c|c|c|c|c|}
\hline \multicolumn{3}{|c|}{ Cytokinin concentration $\left(\mathrm{mgL}^{-1}\right)$} & \multirow{2}{*}{$\begin{array}{c}\text { Shoot induction } \\
(\%)\end{array}$} & \multirow{2}{*}{$\begin{array}{l}\text { No. of shoot/ explant } \\
(\text { mean } \pm \text { SE) }\end{array}$} & \multirow{2}{*}{$\begin{array}{l}\text { Shoot length }(\mathrm{cm}) \\
(\text { mean } \pm \text { SE) }\end{array}$} \\
\hline BAP & KIN & TDZ & & & \\
\hline 0 & 0 & 0 & $0.0 \mathrm{~d}$ & $0.0 \mathrm{~d}$ & $0.0 \mathrm{c}$ \\
\hline 0.2 & - & - & $26.67 \pm 0.08 \mathrm{bcd}$ & $0.93 \pm 0.35 \mathrm{~cd}$ & $0.34 \pm 0.13 \mathrm{bc}$ \\
\hline 0.5 & - & - & $63.33 \pm 0.08 \mathrm{ab}$ & $1.57 \pm 0.39 \mathrm{bcd}$ & $0.95 \pm 0.24 \mathrm{bc}$ \\
\hline 1.0 & - & - & $76.67 \pm 0.07 \mathbf{a}$ & $4.87 \pm 0.70 \mathrm{a}$ & $2.62 \pm 0.29 \mathrm{a}$ \\
\hline 2.0 & - & - & $60.00 \pm 0.09 \mathrm{abc}$ & $2.87 \pm 0.45 \mathrm{~b}$ & $1.04 \pm 0.18 \mathrm{~b}$ \\
\hline 3.0 & - & - & $36.67 \pm 0.08 \mathrm{bcd}$ & $1.13 \pm 0.39 \mathrm{bcd}$ & $0.57 \pm 0.20 \mathrm{bc}$ \\
\hline- & 0.2 & - & $13.33 \pm 0.06 \mathrm{~d}$ & $0.67 \pm 0.30 \mathrm{~cd}$ & $0.32 \pm 0.14 \mathrm{bc}$ \\
\hline- & 0.5 & - & $26.67 \pm 0.08 \mathrm{bcd}$ & $1.03 \pm 0.28 \mathrm{bcd}$ & $0.71 \pm 0.19 \mathrm{bc}$ \\
\hline- & 1.0 & - & $36.67 \pm 0.08 \mathrm{bcd}$ & $1.08 \pm 0.38 \mathrm{bcd}$ & $2.13 \pm 0.31 \mathrm{a}$ \\
\hline- & 2.0 & - & $26.67 \pm 0.08 \mathrm{bcd}$ & $1.33 \pm 0.31 \mathrm{bcd}$ & $0.80 \pm 0.19 \mathrm{bc}$ \\
\hline- & 3.0 & - & $16.67 \pm 0.06 \mathrm{~d}$ & $0.53 \pm 0.22 \mathrm{~cd}$ & $0.38 \pm 0.15 \mathrm{bc}$ \\
\hline- & - & 0.1 & $13.33 \pm 0.06 \mathrm{~d}$ & $1.00 \pm 0.33 \mathrm{bc}$ & $0.82 \pm 0.26 \mathrm{bc}$ \\
\hline- & - & 0.2 & $23.30 \pm 0.07 \mathrm{~cd}$ & $2.30 \pm 0.53 \mathrm{bcd}$ & $0.82 \pm 0.17 \mathrm{bc}$ \\
\hline- & - & 0.5 & $30.00 \pm 0.08 \mathrm{bcd}$ & $1.47 \pm 0.38 \mathrm{bcd}$ & $0.64 \pm 0.16 \mathrm{bc}$ \\
\hline- & - & 1.0 & $20.00 \pm 0.07 \mathrm{~d}$ & $0.90 \pm 0.41 \mathrm{~cd}$ & $0.43 \pm 0.18 \mathrm{bc}$ \\
\hline- & - & 2.0 & $0.0 \mathrm{~d}$ & $0.0 \mathrm{~d}$ & $0.0 \mathrm{c}$ \\
\hline
\end{tabular}

*Means within a column that do not share a letter are significantly different at $p \leq 0.05$ using Tukey’s test 
Based on the current study, BAP was more efficient cytokinin in E. longifolia's multiple shoot induction and proliferation, where the number of shoots per explant was significantly higher at $1.0 \mathrm{mgL}^{-1} \mathrm{BAP}$ treatment as compared to KIN and TDZ. In general, increased concentrations of plant growth regulators over the optimum concentration resulted in reducing the frequency of shoot induction and the number of shoots per explant (Rahimi et al., 2013; Khan et al., 2015; Kazeroonian et al., 2018). Our study also shows that the TDZ was less effective than BAP or KIN and the shoots formed from the TDZcontaining MS, were stunted and failed to elongate even when the shoots were subcultured on PGR-free MS medium. Moreover, a small amount of callus was observed on some explant cultured on the TDZ-containing medium. Low concentrations of TDZ also inhibited shoot elongation as compared to the BAP treatments; hence shoot induction and elongation with BAP treatment was preferred.

\section{Rooting of the shoot and plantlets acclimatization}

Different concentrations of IBA and NAA were added to half-strength MS medium to induce rooting in E. longifolia. In this study, regenerated shoots with $2.5-4.5 \mathrm{~cm}$ in length were excised from the cotyledonary nodes and transferred to the half-strength MS medium supplemented with different concentrations of IBA and NAA or without any auxins (Table 2). Initiation of root was observed even from the shoot cultured on half-strength MS medium without auxins with an average number of $0.26 \pm 0.15$ roots per shoot after three weeks. Although the root formation was observed in MS medium without auxins, the presence of auxins was required to induce a higher number of roots. Table 2 shows that, out of the four concentrations of IBA tested, $0.5 \mathrm{mgL}^{-1}$ of IBA has proven to be the best concentration for rooting, which represents the highest value of rooting $(3.20 \pm 0.50)$. Moreover, the root length was the longest $(3.66 \pm 0.52 \mathrm{~cm})$ and developed relatively normal in the same concentration of IBA $(F i g .2 F, G)$.

Table 2. Effect of different concentrations of IBA and NAA in $1 / 2$ MS medium on root induction from in vitro shoot of Eurycoma longifolia

\begin{tabular}{|c|c|c|c|c|}
\hline \multicolumn{2}{|c|}{$\begin{array}{c}\text { Auxin concentration } \\
\left(\mathrm{mgL}^{-1}\right)\end{array}$} & \multirow[t]{2}{*}{$\begin{array}{c}\text { Rooting respons } \\
\text { (\%) }\end{array}$} & \multirow[t]{2}{*}{$\begin{array}{l}\text { No. of root/ shoot } \\
\quad(\text { mean } \pm \text { SE })\end{array}$} & \multirow[t]{2}{*}{$\begin{array}{l}\text { Root length }(\mathrm{cm} \\
\quad(\text { mean } \pm \text { SE) }\end{array}$} \\
\hline IBA & NAA & & & \\
\hline 0 & 0 & $20.00 \pm 0.10 \mathrm{~b}$ & $0.26 \pm 0.15 \mathrm{e}$ & $0.86 \pm 0.46 \mathrm{~cd}$ \\
\hline 0.2 & - & $33.33 \pm 0.12 \mathrm{ab}$ & $0.53 \pm 0.21 \mathrm{~cd}$ & $1.04 \pm 0.40 \mathrm{c}$ \\
\hline 0.5 & - & $80.00 \pm 0.10$ a & $3.20 \pm 0.50 \mathrm{a}$ & $3.66 \pm 0.52 \mathrm{a}$ \\
\hline 1.0 & _ & $40.00 \pm 013 \mathrm{ab}$ & $0.80 \pm 0.29 \mathrm{bc}$ & $1.28+0.0 .43 \mathrm{c}$ \\
\hline 2.0 & _ & $26.70 \pm 0.11 \mathrm{~b}$ & $0.41 \pm 0.19 \mathrm{~d}$ & $0.90 \pm 0.40 \mathrm{~cd}$ \\
\hline - & 0.2 & $15.13 \pm 0.09 \mathrm{~b}$ & $0.40 \pm 0.18 \mathrm{~d}$ & $0.62 \pm 0.15 \mathrm{~d}$ \\
\hline - & 0.5 & $23.20 \pm 0.10 \mathrm{~b}$ & $1.02 \pm 0.43 \mathrm{~b}$ & $0.90 \pm 0.30 \mathrm{~cd}$ \\
\hline - & 1.0 & $30.33 \pm 0.11 \mathrm{~b}$ & $1.43 \pm 0.34 \mathrm{~b}$ & $2.20 \pm 0.30 \mathrm{~b}$ \\
\hline & 2.0 & $19.10 \pm 0.10 b$ & $0.70 \pm 0.28 \mathrm{bc}$ & $1.26 \pm 0.40 \mathrm{c}$ \\
\hline
\end{tabular}

*Means within a column that do not share a letter are significantly different at $\mathrm{p} \leq 0.05$ using Tukey's test

In the current study, it was observed that no callus was induced around the shoot's bases, whereas the roots were initiated directly from the shoot (Fig. $2 H$ ). Increasing the level of IBA had caused a steady decline in the root formation compared to the medium without auxin (control), which emphasized the fact that a high concentration of auxin in tissue culture conditions could affect root development. It was observed that the platelets 
which had developed root systems before being transferred to soil, seemed to be well-established in the acclimatization stage. In this study, the acclimatization of in vitro plantlets with ex vitro condition was successfully carried out. Initially the plantlets were transferred to the plastic pots $(7.5 \mathrm{~cm}$ diameter) containing an autoclaved jiffy-7 medium and covered with transparent polyethylene bags to maintain high humidity and kept in the growth room for the first 2 weeks. The data has shown that $85 \%$ of plantlets survived and developed into grown plants when transferred into the soil. No variation in leaf morphology was recorded when they were compared to in vivo plants (Fig. 2I).

\section{Discussion}

Direct shoot regeneration protocol provides a potential rapid technique that can be utilized in genetic transformation. In this study, multiple shoots formation was induced from cotyledonary node explants. It has been reported that cotyledonary nodes were the optimal in vitro explants for shoot production in other plants such as Cassia sophera (Parveen and Shahzad, 2010), Sassurealappa Clarke (Groach and Singh, 2015) and Cucumis sativus L. (Venkatachalam et al., 2018). In this study cytokinins such as; BAP, KIN and TDZ were tested for their in vitro effects and showed different responses of shoot formation. BAP at low concentration of $0.2 \mathrm{mgL}^{-1}$ BAP showed only $20 \%$ shoot induction with an average of 0.83 shoots number. However, BAP at $1.0 \mathrm{mgL}^{-1}$ produced the highest shoot induction (76.7\%), with 4.87 number of shoots. Nayak et al. (2013) reported that in Withania somnifera the best result was recorded with $1.0 \mathrm{mgL}^{-1} \mathrm{BAP}$ and $100 \%$ of the cotyledonary nodes exhibited shoot initiation within 12 days. In addition, Kumar and Chandre (2009) reported that among the three cytokinins (BAP, KIN and TDZ) used, BAP was the best cytokinin for inducing the maximum number of shoots from the apical meristem of Stylosanthes seabrana. Their result also showed that $1.0 \mathrm{mgL}^{1} \mathrm{KIN}$ induced $63.3 \%$ multiple shoots with a lower number of shoots $(2.40$ shoot per explant) on average.

Shoot induction decreased (36.7\%) with an average of shoot number $1.13 \pm 0.39$ at a higher concentration of BAP concentration (Table 1). Venkatachalam and Kavipriya (2012) reported a similar result of the frequency of shoot regeneration from the cotyledonary node of Arachis hypogaea L. using two cytokinins BAP and KIN with different concentrations. KIN induced the lower percentage of the shoot. Similar observations on the effectiveness of BAP at lower concentration detected in several plant species such as Ricinus communis (Alam et al., 2010); Lens culinaris (Bermejoa et al., 2012); Psoralea corylifolia (Pandey et al., 2013) and Vitex negundo (Groach et al., 2014).

Formation of stunted shoots was a common problem with MS medium containing TDZ, as have been reported for several plant species, such as Cassia siamea (Parveen et al., 2010); Withania somnifera (Nayak et al., 2013); Elaeocarpus blascoi (Siva et al., 2015) and Platanus acerifolia (Bao et al., 2017). However, prolonged exposure of regenerated shoots to medium supplemented with high concentrations of TDZ resulted in distortion in the shoots. Similar observations have also been reported in other studies (Parveen and Shahzad, 2010; Ahmed and Anis, 2012; Dewir et al., 2018). The proliferation of multiple shoots could be stimulated by adding cytokinins to the regeneration medium, but it can inhibit their further growth and elongation. Therefore, elongation of the shoot could be consistently inhibited by TDZ due to its high cytokinin activity (Kumar and Reddy, 2012; Siddique et al., 2015). Similarly, in several studies on other plant species such as Cassia sophera (Parveen and Shahzad, 2010), Curculigo 
latifolia (Babaei et al., 2014) and Jatropha curcas (Aishwariya et al., 2015) it has been reported that the higher concentrations of TDZ resulted in stunted shoot and callus production.

It has been reported that with an increase in concentrations of cytokinins, the responding frequency of explants and the number of shoot regeneration was increased up to certain limits and then reduced markedly (Naing et al., 2015; Seo et al., 2017; Kumari and Harsh, 2018). Cotyledonary nodes as an explant have been also reported to be an efficient starting material to induce multiple shoots in many of other plant species such as Sterculia urens Roxb (Devi et al., 2011), Citrullus colycynthis (Meena et al., 2014) and Mucuna bracteata DC. (Aziz et al., 2018). These nodes had a better regeneration response compared to the other parts of the plant due to its regenerative axillary meristem cells (Hsieh et al., 2017).

Rooting of in vitro regenerated shoots is an important step for successful in vitro regeneration of whole plantlets (Toppo et al., 2012; Shekhawat et al., 2015). It produces the whole plant that can survive in ex vitro conditions. Roots could be only induced from the shoots which are not succulent or fragile. Development of roots should be directly from the base of the shoot and no callus should be formed to provide a good vascular connection between shoot and root (Anwar et al., 2010). In general, auxins are used for root induction, but they might prevent the continued growth of roots if they remain on the same rooting medium (Harahap et al., 2014). IBA is an auxin that is widely used for root induction in in vitro cultures (Baque et al., 2010; Patel et al., 2014). A study conducted by Hussein et al. (2005) on shoot regeneration from shoot tip explants of Eurycoma longifolia found out that, out of different concentrations of IBA tested only 0.4 and $0.5 \mathrm{mgL}^{-1}$ were able to induce roots from the in vitro plantlets. This is in agreement with our study, which shows that $0.5 \mathrm{mgL}^{-1}$ of IBA is the best concentration for root induction of E. longifolia. IBA at $0.5 \mathrm{mgL}^{-1}$ produced the highest percentage of roots (80\%) with an average 3.20 root per shoot (Table 2). Kumar and Nand (2015) reported a similar observation with the same concentration of auxin (IBA $0.5 \mathrm{mgL}^{-1}$ ) in half-strength MS medium for root induction from Asteracantha longifolia. However, NAA is more potent than IBA and IAA for the induction of adventitious roots from leaf explants of E. longifolia (Hussein et al., 2012).

The superiority of IBA over the other auxins in the induction of root has been previously reported in other studies (Parveen and Shahzad, 2010; Hussein et al., 2012; Agarwal et al., 2015; Bohra et al., 2016). A previous study by Hussein et al. (2005) on E. longifolia reported that MS medium supplemented with NAA or IAA, tended to form callus at shoot's bases. Whereas, only IBA showed a sign of direct root formation. These observations could be due to the fact that IBA is more resistant to chemical degradation than other auxins during the autoclaving of culture media, or it might be due to the location of auxin receptors of the plant tissues, where different types of auxin react differently based on the position of its receptor (Nissen and Sutter, 1990; Zhao et al., 2014; Andujar et al., 2019).

Micropropagated plantlets, which are developed in a controlled microenvironment might desiccate and die if they were directly placed at a low level of humidity or higher light level that is stressful as compared to in vitro conditions. Moreover, during the acclimatization process the plantlets have poor photosynthetic capability and the leaves act as a source of carbohydrates for the newly developing leaves. This poor photosynthetic capability could cause the deaths of some of the micropropagated plantlets (Chaari-Rkhis et al., 2015). Syafiqah et al. (2017) suggested that the usage of $100 \%$ jiffy 
was the suitable potting medium for the acclimatization of Labisia pumila plantlets. Yahya et al. (2015) reported that jiffy-7 was the best potting media for Tongkat Ali acclimatization. Their results showed that $100 \%$ of plantlets survival was obtained with jiffy-7 medium.

\section{Conclusion}

In conclusion, the present study described a rapid and simple protocol for mass propagation. The result showed that the high frequency of multiple shoot induction was possible from the cotyledonary node explants of E. longifolia plant. The complete regeneration system described here can be achieved within 12 weeks; a much shorter period as compared to the germination in forest sandy soils in nature which normally takes eight months to grow up to the same height of the in vitro propagated plants. This protocol would be beneficial for large-scale propagation that could meet the increasing demand of the pharmaceutical industry. However, it can be used to perform further experiments to obtain transgenic plants or other biotechnological approaches.

Acknowledgements. The authors would like to thank the Biodiversity Unit at Institute of Bioscience, University Putra Malaysia for providing the plant material for this research.

\section{REFERENCES}

[1] Agarwal, T., Gupta, A. K., Patel, A. K., Shekhawat, N. S. (2015): Micropropagation and validation of genetic homogeneity of Alhagi maurorum using SCoT, ISSR and RAPD markers. - Plant Cell, Tissue and Organ Culture 120: 313-323.

[2] Ahmed, M. R., Anis, M. (2012): Role of TDZ in the quick regeneration of multiple shoots from nodal explant of Vitex trifolia L.-an important medicinal plant. - Applied biochemistry and biotechnology 168: 957-966.

[3] Aishwariya, V., Ramrao, R. K., Kokila, D. E., Arul, L., Sudhakar, D., Kumar, K. K., Balasubramanian, P. (2015): Impact of TDZ (thidiazuron) pulse treatment in single and multiple shoot formation in calli of Jatropha curcas L. - International Journal of Advanced Research 3: 879-884.

[4] Alam, I., Sharmin, S., Mondal, S., Alam, J., Khalekuzzaman, M., Anisuzzaman, M., Alam, M. (2010): In vitro Micropropagation through Cotyledonary Node Culture of Castor Bean (Ricinus communis L.). - Australian Journal of Crop Science 4: 81-84.

[5] Alsarhan, A., Sultana, N., Al-Khatib, A., Abdul Kadir, M. R. (2014): Review on some Malaysian traditional medicinal plants with therapeutic properties. - Journal of Basic and Applied Sciences 10: 149-159.

[6] Andujar, I., Gomez, D., Perez, L., Vicente, O., Lorenzo, J. C. (2019): Auxins, auxin transport inhibitors, and competitors for auxin receptors do not show statistically significant differences in 212 molecular descriptors. - Romanian Biotechnological Letters 24(3): 407-411.

[7] Anwar, F., Sharmila, P., Saradhi, P. P. (2010): No more recalcitrant: Chickpea regeneration and genetic transformation. - African Journal of Biotechnology 9: 782-797.

[8] Ayob, Z., Wagirana, A., Samada, A. A. (2013): Potential of Tissue Cultured Medicinal Plants in Malaysia. - Jurnal Teknologi 62: 111-117.

[9] Aziz, N. A., Tan, B. C., Othman, R. Y., Khalid, N. (2018): Efficient micropropagation protocol and genome size estimation of an important cover crop, Mucuna bracteata DC. ex Kurz. - Plant Cell, Tissue and Organ Culture 132: 267-278. 
[10] Babaei, N., Abdullah, P., Ashikin, N., Saleh, G., Lee Abdullah, T. (2014): An efficient in vitro plantlet regeneration from shoot tip cultures of Curculigo latifolia, a medicinal plant. - The Scientific World Journal, Article ID: 275028.

[11] Bao, Z., Zhang, Y., Shao, C., Zhang, J., Liu, G., Bao, M. (2017): A rapid and efficient in vitro shoot regeneration protocol using cotyledons of London plane tree (Platanus acerifolia Willd.). - Plant Growth Regulation 83: 245-252.

[12] Baque, M. A., Hahn, E. J., Paek, K. Y. (2010): Induction mechanism of adventitious root from leaf explants of Morinda citrifolia as affected by auxin and light quality. - In Vitro Cellular \& Developmental Biology-Plant 46(1): 71-80.

[13] Bermejo, C., Espósito, M., Cravero, V., Anido, F., Cointry, E. (2012): In vitro plant regeneration from cotyledonary nodes of recombinant inbred lines of lentil. - Scientia Horticulturae 134: 13-19.

[14] Bhat, R., Karim, A. A. F. (2010): Tongkat Ali (Eurycoma Longifolia Jack): A Review on Its Ethnobotany and Pharmacological Importance. - Fitoterapia 81: 669-679.

[15] Bohra, P., Waman, A. A., Sathyanarayana, B. N., Umesha, K., Gowda, B. (2016): Influence of different growth regulators on in vitro multiplication of mixed diploid banana (Musa AB). - Proceedings of the National Academy of Sciences, India Section B: Biological Sciences 86: 179-185.

[16] Chaari-Rkhis, A., Maalej, M., Chelli-Chaabouni, A., Fki, L., Drira, N. (2015): Photosynthesis parameters during acclimatization of in vitro-grown olive plantlets. Photosynthetica 53: 613-616.

[17] Chua, L. S., Nor Amaiza, M., Jason, C. H. N., Ting, H. L., Chew, T. L., Mohamad, R. S., Ramlan, A. (2011): LC-MS/MS-Based Metabolites of Eurycoma longifolia (Tongkat Ali) in Malaysia (Perak and Pahang). - Journal of Chromatography B 879: 3909-3919.

[18] Devi, P. S., Arundathi, A., Rao, T. R. (2011): Multiple shoot induction and regeneration of whole plants from cotyledonary node and nodal explants of Sterculia urens Roxb., a gum yielding tree. - Journal of plant biochemistry and biotechnology 20: 161-165.

[19] Dewir, Y. H., Naidoo, Y., Silva, J. A. T. (2018): Thidiazuron-induced abnormalities in plant tissue cultures. - Plant cell reports 37: 1451-1470.

[20] Groach, R., Yadav, K., Singh, N. (2014): In vitro studies on Vitex negundo, a potent medicinal plant. - Environmental and Experimental Biology 12: 149-153.

[21] Groach, R., Singh, N. (2015): In vitro Direct Regeneration from Cotyledonary Node of Sassurealappa clarke - Avaluable Endangered Medicinal Herb. - International Journal of Agricultural Science and Research 5: 361-66.

[22] Harahap, F., Poerwanto, R., Suharsono, S. C., Rahayu, S. (2014): In vitro Growth and Rooting of Mangosteen (Garcinia mangostana L.) on Medium with Different Concentrations of Plant Growth Regulator. - HAYATI Journal of Biosciences 21: 151158.

[23] Hsieh, Y. F., Jain, M., Wang, J., Gallo, M. (2017): Direct organogenesis from cotyledonary node explants suitable for Agrobacterium-mediated transformation in peanut (Arachis hypogaea L.). - Plant Cell, Tissue and Organ Culture 128: 161-175.

[24] Hussein, S., Ibrahim, R., Kiong, A. L. P., Nor, A. M. F., Daud, S. K. (2005): Multiple shoots formation of an important tropical medicinal plant, Eurycoma longifolia Jack. Plant Biotechnology 22: 49-351.

[25] Hussein, S., Ling, A. P. K., Ng, T. H., Ibrahim, R., Paek, K. Y. (2012): Adventitious roots induction of recalcitrant tropical woody plant, Eurycoma longifolia. - Romanian Biotechnological Letters 17: 7026-7035.

[26] Isah, T. (2016): Induction of somatic embryogenesis in woody plants. - Acta Physiologiae Plantarum 38: 118.

[27] Jamshidi-Kia, F., Lorigooini, Z., Amini-Khoei, H. (2018): Medicinal plants: Past history and future perspective. - Journal of Herbmed Pharmacology 7(1): 1-7. 
[28] Juturu, V. N., Mekala, G. K., Kirti, P. (2015): Current status of tissue culture and genetic transformation research in cotton (Gossypium spp.). - Plant Cell, Tissue and Organ Culture (PCTOC) 120: 813-839.

[29] Kazeroonian, R., Mousavi, A., Jari, S. K., Tohidfar, M. (2018): Factors Influencing in vitro Organogenesis of Chrysanthemum morifolium cv. 'Resomee Splendid'. - Iranian Journal of Biotechnology 16(2): e1454.

[30] Keng, C. L., Sai, S. T., Teo, C. K. H. (2002): A preliminary study on the germination of Eurycoma longifolia Jack (Tongkat Ali) seeds. - Pertanika Journal of Tropical Agricultural Science 25: 27-34.

[31] Khan, N., Ahmed, M., Hafiz, I., Abbasi, N., Ejaz, S., Anjum, M. (2015): Optimizing the concentrations of plant growth regulators for in vitro shoot cultures, callus induction and shoot regeneration from calluses of grapes. - Oeno One 49(1): 37-45.

[32] Kumar, S., Chandra, A. (2009): Direct plant regeneration via multiple shoot induction in Stylosanthes seabrana. - Cytologia 74: 391-399.

[33] Kumar, N., Reddy, M. P. (2012): Thidiazuron (TDZ) induced plant regeneration from cotyledonary petiole explants of elite genotypes of Jatropha curcas: a candidate biodiesel plant. - Industrial crops and products 39: 62-68.

[34] Kumar, M. S., Nandi, S. C. (2015): High frequency plant regeneration with histological analysis of organogenic callus from internode explants of Asteracantha longifolia Nees. Journal of Genetic Engineering and Biotechnology 13: 31-37.

[35] Kumari, A., Harsh, K. (2018): Effect of Cytokinin on Multiple Shoot Regeneration in Shoot Apical Culture of Physalis minima L. - An Important Fruit and Medicinal Plant. International Journal of Current Microbiology and Applied Sciences 7: 3115-3121.

[36] Lulu, T., Park, S. Y., Ibrahim, R., Paek, K. Y. (2015): Production of biomass and bioactive compounds from adventitious roots by optimization of culturing conditions of Eurycoma longifolia in balloon-type bubble bioreactor system. - Journal of Bioscience and Bioengineering 119: 712-717.

[37] Mahmood, M., Normi, R., Subramaniam, S. (2010): Optimization of suitable auxin application in a recalcitrant woody forest plant of Eurycoma longifolia (Tongkat Ali) for callus induction. - African Journal of Biotechnology 9: 8417-8428.

[38] Meena, M. C., Meena, R. K., Meena, V. P., Patni, V. (2014): Efficient method for in vitro plant regeneration from cotyledonary node explants of Citrullus colocynthis (Linn.) Schrad. - World Journal of Pharmaceutical Sciences 3: 1140-1148.

[39] Murashige, T., Skoog, F. (1962): A revised medium for rapid growth and bio assays with tobacco tissue cultures. - Acta Physiologia Plantarum 15: 473-497.

[40] Naing, A. H., Lim, K. B., Park, K. I., Chung, M. Y., Kim, C. K. (2015): A revised medium for rapid growth and bio assays with tobacco tissue cultures. - Physiologia Plantarum 15: 473-497.

[41] Nayak, S. A., Kumar, S., Satapathy, K., Moharana, A., Behera, B., Barik, D. P., Acharya, L., Mohapatra, P. K., Jena, P. K., Naik, S. K. (2013): In vitro plant regeneration from cotyledonary nodes of Withania somnifera (L.) Dunal and assessment of clonal fidelity using RAPD and ISSR markers. - Acta physiologiae plantarum 35: 195-203.

[42] Nissen, S. J., Sutter, E. G. (1990): Stability of IAA and IBA in nutrient medium to several tissue culture procedures. - HortScience 25(7): 800-802.

[43] Pandey, P., Mehta, R., Upadhyay, R. (2013): In vitro propagation of an endangered medicinal plant Psoralea corylifolia Linn. - Asian Journal of Pharmaceutical and Clinical Research 6: 115-118.

[44] Parveen, S., Shahzad, A. (2010): TDZ-induced high frequency shoot regeneration in Cassia sophera Linn. via cotyledonary node explants. - Physiology and Molecular Biology of Plants 16: 201-206.

[45] Parveen, S., Shahzad, A., Saema, S. (2010): In vitro plant regeneration system for Cassia siamea Lam., a leguminous tree of economic importance. - Agroforestry Systems 80: 109116. 
[46] Patel, A. K., Phulwaria, M., Rai, M. K., Gupta, A. K., Shekhawat, S., Shekhawat, N. S. (2014): In vitro propagation and ex vitro rooting of Caralluma edulis (Edgew.) Benth. \& Hook. f.: an endemic and endangered edible plant species of the Thar Desert. - Scientia Horticulturae 165: 175-180.

[47] Rahimi, S., Naderi, R., Ghaemaghami, S. A., Kalatejari, S., Farham, B. (2013): Study on effects of different Plant Growth Regulators types in shoot regeneration and node formation of Sutsuki Azalea (Rhododendron indicum): a commercially important bonsai. - Procedia Engineering 59: 240-246.

[48] Rahmawati, A., Esyanti, R. R. (2014): Analysis of Secondary Metabolite Production in Somatic Embryo of Pasak Bumi (Eurycoma longifolia Jack.). - Procedia Chemistry 13: $112-118$.

[49] Rehman, S. U., Choe, K., Yoo, H. H. (2016): Review on a traditional herbal medicine, Eurycoma longifolia Jack (Tongkat Ali): its traditional uses, chemistry, evidence-based pharmacology and toxicology. - Molecules 2: 331.

[50] Rodziah, K., Madihah, M. N. (2015): Thidiazuron induces high frequency direct somatic embryogenesis growth from cotyledon culture of Eurycoma longifolia. - Sains Malaysiana 44: 913-920.

[51] Seo, S. G., Ryu, S. H., Zhou, Y., Kim, S. H. (2017): Development of an efficient protocol for high-frequency regeneration system in Hibiscus syriacus L. - Journal of Plant Biotechnology 44: 164-170.

[52] Shekhawat, M. S., Kannan, N., Manokari, M., Ravindran, C. P. (2015): In vitro regeneration of shoots and ex vitro rooting of an important medicinal plant Passiflora foetida L. through nodal segment cultures. - Journal of Genetic Engineering and Biotechnology 13: 209-214.

[53] Siddique, I., Bukhari, N. A. W., Perveen, K., Siddiqui, I. (2015): Influence of plant growth regulators on in vitro shoot multiplication and plantlet formation in Cassia angustifolia Vahl. - Brazilian Archives of Biology and Technology 58: 686-691.

[54] Singh, A. S., Kumari, S., Modi, A. R., Gajera, B. B., Narayanan, S., Kumar, N. (2015): Role of conventional and biotechnological approaches in genetic improvement of castor (Ricinus communis L.). - Industrial Crops and Products 74: 55-62.

[55] Singh, C. R. (2018): Review on problems and its remedy in plant tissue culture. - Asian Journal of Biological Sciences 11: 165-172.

[56] Siva, S., Priya, T. A., Balasubramanian, P., Manimekalai, V., Ravichandran, R. (2015): In vitro regeneration of an endangered tree-Elaeocarpus blascoi Weibel. (Rudraksa) from Southern Western Ghats, Tamil Nadu, India. - European Journal of Biotechnology and Bioscience 3: 62-66.

[57] Syafiqah, N. S. B., Farah Fazwa, M. A., Siti Suhaila, A. R., Norhayati, S., Zaki, M., Masitah, M. T. (2017): Acclimatization of KFeFRIM01: A Superior Clone of Labisia pumila var. alata. - International Journal of Environmental \& Agriculture Research 3: 2454-1850.

[58] Thu, H. E., Mohamed, I. N., Hussain, Z., Mohamed, N., Shuid, A. N. (2016): Eurycoma longifolia, a Malaysian medicinal herb, significantly upregulates proliferation and differentiation in pre-osteoblasts (MC3T3-E1): An in vitro model. - International Journal of Pharmaceutical Sciences 8: 199-204.

[59] Toppo, D. D., Singh, G., Purshottam, D. K., Misra, P. (2012): Improved in vitro rooting and acclimatization of Jatropha curcas plantlets. - Biomass and bioenergy 44: 42-46.

[60] Uprety, Y., Hugo, A., Archana, D., Nancy, J. (2012): Traditional Use of Medicinal Plants in the Boreal Forest of Canada: Review and Perspectives. - Journal of Ethnobiology \& Ethnomedicine 8: 7.

[61] Venkatachalam, P., Kavipriya, V. (2012): Efficient Method for In vitro Plant Regeneration from Cotyledonary Node Explants of Peanut (Arachis hypogaea L.). - International Conference on Nuclear Energy, Environmental and Biological Sciences. Bangkok (Thailand). 
[62] Venkatachalam, P., Jinu, U., Sangeetha, P., Geetha, N., Sahi, S. V. (2018): High frequency plant regeneration from cotyledonary node explants of Cucumis sativus L. cultivar 'Green Long'via adventitious shoot organogenesis and assessment of genetic fidelity by RAPDPCR technology. -3 Biotech 8(1): 60.

[63] Yahya, M. F., Hassan, N. H., Abdullah, N., Rahman, S. S. A., Ismail, H., Abdullah, M. Z., Ariff, F. F. M., Ngah, M. L., Koter, R., Khalid, R., Abdullah, R. (2015): Acclimatization of Eurycoma longifolia (Tongkat Ali) plantlets to ex vitro conditions. - Journal of Tropical Resources and Sustainable Science 3: 129-131.

[64] Zeng, S., Zhang, Y., Teixeira da Silva, J. A., Wu, K., Zhang, J., Duan, J. (2014): Seed biology and in vitro seed germination of Cypripedium. - Critical reviews in biotechnology 34: 358-371.

[65] Zhao, Y., Xing, L., Wang, X., Hou, Y. J., Gao, J., Wang, P., Zhu, J. K. (2014): The ABA receptor PYL8 promotes lateral root growth by enhancing MYB77-dependent transcription of auxin-responsive genes. - Science Signaling 7(328): ra53. 